\title{
CULTURAS QUILOMBOLAS INVISIBILIZADAS NOS CURRÍCULOS DE FORMAÇÃO DE PROFESSORES: caminhos em Freire para a humanização
}

\author{
Marina Graziela Feldmann \\ Andréia Regina Silva Cabral Libório
}

\section{Resumo}

O presente artigo pondera a invisibilidade acerca de determinadas culturas nos currículos, sobretudo as comunidades quilombolas, bem como da importância dessas serem reconhecidas, acolhidas e valorizadas no seio das instituições educativas, desde as políticas públicas aos currículos e as práticas educativas. Apresenta como objetivo central: compreender as contribuições de Paulo Freire para o processo de humanização dos sujeitos e culturas invisibilizadas nos currículos, especificamente a dos povos quilombolas. A metodologia baseia-se na abordagem qualitativa e a análise a partir do referencial teórico e legislações/documentos selecionados. Com as contribuições de Freire (1981, 1987, 1997); García (1999); Feldmann (2009); Chiavenato (2012); Arroyo (2013); Santomé (2013); Chizotti (2014); Silva (2016) entre outros. Os resultados: revelam a necessidade da compreensão e de um olhar mais sensível a respeito do apagamento, ausência ou silenciamento de determinadas culturas, nos currículos escolares e de formação de professores em detrimento de uma cultura dominante e hegemônica e, a partir das contribuições freireanas evidencia-se que o caminho para a humanização dessas culturas, intermediada por uma pedagogia crítico e emancipadora para libertação e "anti-marginalização", precisa partir do "ser para si” no que concerne as suas próprias histórias e de suas realidades concretas, de modo a reconhecer-se e acolher-se as suas especificidades e diversidade cultural, assim como a busca do "ser mais" por meio de suas vozes e relações com o mundo. Ademais, fazem-se necessários a visibilidade e o conhecimento sobre os povos/comunidades quilombolas que contribuíram e contribuem na constituição da sociedade brasileira.

Palavras-chave: culturas invisibilizadas; currículos; comunidades quilombolas; humanização; Paulo Freire.

\section{QUILOMBOLAS CULTURES INVISIBLE IN THE TEACHER EDUCATION CURRICULUM: paths in Freire for humanization}

\begin{abstract}
This article considers the invisibility of certain cultures in the curricula, especially communities quilombolas, as well as the importance of these being recognized, welcomed and valued within educational institutions, from public policies to curricula and educational practices. Its main objective is to understand the contributions of Paulo Freire to the process of humanization of subjects and cultures invisible in the curricula, specifically that of quilombola peoples. The methodology is based on the qualitative approach and the analysis based on the theoretical framework and selected legislation / documents. With the contributions of Freire (1981, 1987, 1997); García (1999); Feldmann (2009); Chiavenato (2012); Arroyo (2013), Santomé (2013); Chizotti (2014); Silva (2016) among others. The results: reveal the need for understanding and a more sensitive view of the erasure, absence or silencing of certain cultures, in school curricula and teacher training to the detriment of a dominant and hegemonic culture and, based on Freire's contributions, It is felt that the path towards the humanization of these cultures, mediated by a critical and emancipatory pedagogy for liberation and "anti-marginalization", needs to start from "being for oneself" with regard to their own histories and their concrete realities, in order to recognize themselves and welcome their specificities and cultural diversity, as well as the search for "being more" through their voices and
\end{abstract}


DOI: $10.12957 /$ teias.2021.62074

relationships with the world. Furthermore, visibility and knowledge about the quilombola peoples/communities that contributed and contribute to the constitution of Brazilian society are necessary. Keywords: invisible cultures; curriculum; communities quilombolas; humanization; Paulo Freire.

\section{LAS CULTURAS QUILOMBOLAS INVISIBLES EN EL CURRÍCULO DE EDUCACIÓN DEL MAESTRO: caminos en Freire para la humanización}

Resumen

Este artículo considera la invisibilidad de ciertas culturas en los currículos, especialmente las comunidades quilombolas, así como la importancia de que estas sean reconocidas, acogidas y valoradas dentro de las instituciones educativas, desde las políticas públicas hasta los currículos y prácticas educativas. Su principal objetivo es comprender los aportes de Paulo Freire al proceso de humanización de asignaturas y culturas invisibles en los currículos, específicamente el de los pueblos quilombolas. La metodología se basa en el enfoque cualitativo y el análisis basado en el marco teórico y la legislación / documentos seleccionados. Con los aportes de Freire (1981, 1987, 1997); García (1999); Feldmann (2009); Chiavenato (2012); Arroyo (2013), Santomé (2013); Chizotti (2014); Silva (2016) entre otros. Los resultados: revelan la necesidad de comprensión y una visión más sensible del borrado, ausencia o silenciamiento de determinadas culturas, en los currículos escolares y en la formación del profesorado en detrimento de una cultura dominante y hegemónica y, a partir de los aportes de Freire, se percibe que el camino hacia la humanización de estas culturas, intermediado por una pedagogía crítica y emancipadora para la liberación y la "antimarginación", debe partir del "ser para uno mismo" en relación con sus propias historias y sus realidades concretas, para reconocerse y acoger sus especificidades y diversidad cultural, así como la búsqueda de "ser más" a través de sus voces y relaciones con el mundo. Además, es necesario tener visibilidad y conocimiento sobre los pueblos/comunidades quilombolas que han contribuido y contribuyen a la constitución de la sociedad brasileña.

Palabras clave: culturas invisibles; currículum; comunidades quilombolas; humanización; Paulo Freire.

\section{INTRODUÇÃO}

Ao longo das discussões que temos realizado no Curso do Programa de Pós-Graduação Stricto Sensu - Doutorado em Educação: Currículo, assim como nos estudos do Grupo de Pesquisa do Conselho Nacional de Desenvolvimento Científico e Tecnológico (CNPq) "Formação de Professores e Cotidiano Escolar" da Pontifícia Universidade Católica de São Paulo (PUC/SP), temos a oportunidade de refletir acerca das diversidades em suas diversas faces e linguagens, as quais, comumente, são invisibilizadas no âmbito do currículo escolar e de formação de professores.

Além disso, evidenciamos o legado de Paulo Freire com as contribuições no âmbito da educação emancipadora e libertadora por meio de uma filosofia humanizadora, que busca a intervenção e a transformação da realidade, sobretudo das classes populares e dos sujeitos historicamente oprimidos, partindo da própria realidade, vivência e conhecimentos dos educandos.

O presente artigo pondera a respeito da invisibilidade de determinadas culturas nos currículos, especialmente as comunidades quilombolas, bem como da importância de estas serem reconhecidas, acolhidas e valorizadas no seio das instituições educativas, desde as políticas públicas até os currículos e as práticas educativas. Apresenta como objetivo central: compreender as contribuições de Paulo Freire para o processo de humanização dos sujeitos e culturas invisibilizadas nos currículos, especificamente a dos povos quilombolas. 
A base teórica e de análise ancora-se no levantamento bibliográfico a partir de contribuições de Freire (1981, 1987, 1997); García (1999); Feldmann (2009); Chiavenatto (2012); Arroyo (2013); Santomé (2013); Santiago, Akkari, Marques (2013); Silva (2016); Feldmann e Masetto (2017) entre outros, e de análise de documentos (legislações, relatórios e outras publicações institucionais) acerca da temática.

A metodologia baseia-se na abordagem qualitativa por possibilitar maior aproximação com o tema investigado e, segundo Chizzotti (2014, p. 53), à luz de Cicourel (1964), permite aos pesquisadores a afirmação e o elo "[...] da investigação com os problemas ético-políticos e sociais, declaram-se comprometidos com a prática, com a emancipação humana e a transformação social $[\ldots]]^{\prime}$.

As concepções freireanas compreendem a educação como um fenômeno humano, a educação e os educadores não podem ser neutros e a ação educativa não pode considerar o ser humano de forma coisificada para ser "domesticado".

Dessarte, discutimos a partir de uma indagação a respeito da invisibilidade de determinadas culturas no currículo, como é o caso das comunidades e/ou povos quilombolas, e propomos um diálogo em Freire, buscando refletir acerca de possíveis caminhos para a humanização das culturas silenciadas nos currículos. Por fim realçamos a existência das comunidades quilombolas na contemporaneidade, com ênfase na necessidade de conhecer, reconhecer, valorizar e dar visibilidade a esse povo que muito contribuiu e contribui para a construção da sociedade brasileira, mas é relegado ao esquecimento e ao congelamento de sua história no período colonial imperial.

\section{CULTURAS SÃO INVISIBILIZADAS NOS CURRÍCULOS ESCOLARES?}

Essa questão pode nos parecer fácil de responder com um simples sim, entretanto é mais complexo, pois há uma série de indagações, concepções, implicações, contradições e problematizações que nos levam a refletir de forma mais reiterada acerca da referida indagação: Por que determinadas culturas são invisíveis ou até mesmo apagadas nos currículos, seja no de formação de professores ou escolar e nas práticas educativas?

As teorias do currículo nos ensinam e justificam por que um conhecimento é selecionado e considerado válido no currículo, e não outro, e tal fato ocorre pelas relações de poder que são imbricadas e separam uma teoria da outra (tradicional, crítica e pós-crítica). Por conseguinte, essas relações refletem na constituição dos currículos que tendem a representar o conhecimento de determinada classe (a dominante) à sociedade, para a conservação e manutenção de um status quo (SILVA, 2016).

Nesse sentido, Freire (1981, p. 32) enfatiza que:

$\mathrm{Na}$ estrutura social, enquanto dialetização entre a infra e a supraestrutura, não há permanência da permanência nem mudança da mudança, mas o empenho de sua preservação em contradição com o esforço por sua transformação. Daí que não possa ser o trabalhador social, como educador que é, um técnico friamente neutro. Silenciar sua opção, escondê-la no emaranhado de suas técnicas ou disfarçá-la com a proclamação de sua neutralidade não significa na verdade ser neutro mas, ao contrário, trabalhar pela preservação do "status quo".

Portanto, culturas são invisibilizadas, apagadas e silenciadas no currículo, aquelas que comumente são subartenizadas e minorizadas. 
Santomé (2013) apresenta algumas categorias relativas a atitudes desse "currículo turístico", que invisibiliza, apaga e silencia a diversidade cultural no currículo, segundo exposto no Quadro 1.

Quadro 1: Atitudes que evidenciam um "Currículo Turístico"

\begin{tabular}{|c|c|c|}
\hline Atitudes & Abordagem do Tema & Exemplo \\
\hline TRIVIALIZAÇÃO & Superficial/Banal & $\begin{array}{l}\text { Apresenta somente um aspecto, } \\
\text { relacionado à alimentação ou ritos, } \\
\text { festejos, folclore, vestuário, festivos, } \\
\text { habitação etc. }\end{array}$ \\
\hline SOUVENIR & $\begin{array}{l}\text { Como uma viagem turística } \\
\text { ou dado excêntrico/ com uma } \\
\text { presença quantitativa pouco } \\
\text { importante }\end{array}$ & $\begin{array}{l}\text { Apenas em uma unidade didática; } \\
\text { disponibilidade de poucos recursos } \\
\text { didáticos pedagógicos - livros, } \\
\text { brinquedos etc. }\end{array}$ \\
\hline DESCONECTAR & $\begin{array}{l}\text { No "O dia de" ... carregado } \\
\text { de estereótipo e preconceito }\end{array}$ & $\begin{array}{l}\text { Aborda-se o tema somente em um } \\
\text { dia específico, descontextualizado da } \\
\text { realidade }\end{array}$ \\
\hline ESTERIOTIPAGEM & $\begin{array}{r}\text { Por meio de imagens } \\
\text { estereotipadas e situações } \\
\text { pertencentes aos coletivos }\end{array}$ & $\begin{array}{c}\text { Representação social estereotipada } \\
\text { ou total ausência desta, por exemplo: } \\
\text { nos livros didáticos }\end{array}$ \\
\hline TERGIVERSAÇÃO & $\begin{array}{c}\text { Deforma ou oculta a } \\
\text { história e as origens - caso } \\
\text { mais perverso do tratamento } \\
\text { curricular - naturaliza } \\
\text { situações de opressão }\end{array}$ & $\begin{array}{l}\text { Busca justificativas e argumentos } \\
\text { baseados na estrutura familiar - } \\
\text { "psicologização dos problemas" - } \\
\text { dotação genética deficitária }\end{array}$ \\
\hline
\end{tabular}

Fonte: As pesquisadoras, 2021 - Adaptado de Santomé, 2013.

García (1999, p. 91) realça que há uma tendência do currículos de formação inicial de professores para o desenvolvimento de determinados "conhecimentos profissionais", tais como: pedagógico, psicológico e científico, logo, o conhecimento referente ao contexto e às diversidades culturais não é incorporado aos "componentes dos conhecimentos" necessários à formação docente, deste modo, tanto os/as professores/as em formação, quanto os/as professores/as formadores/as precisam desenvolvê-los, dentre outros conhecimentos essenciais, uma vez que eles/as tendem a reproduzir o que adquiriram em sua formação inicial, a qual comumente não compreende tais conhecimentos. 
Um diálogo em Freire: Caminhos para a humanização das culturas silenciadas

Ao partirmos dos estudos de Freire no campo da alfabetização de jovens e adultos, camponeses e trabalhadores, entendemos que o processo do ensinar e do aprender não pode ser alheio à realidade concreta dos educandos, pois essa aprendizagem demanda uma significação daquilo que se ensina. Segundo o autor, a educação bancária não estimula o desenvolvimento da criatividade e expressividade dos seres humanos, pelo contrário:

[...] a educação que costumo chamar de "bancária", em que o educador substitui a expressividade pela doação de expressões que o educando deve ir "capitalizando". Quanto mais eficientemente o faça tanto melhor educando será considerado (FREIRE, 1981, p. 20).

Desse modo, essa prática mecânica e reprodutora da educação bancária tonifica o "silêncio" das classes populares, o que jamais se constituirá como uma ferramenta que propicia a compreensão, a consciência crítica e a transformação da realidade. É necessária, por conseguinte, a aprendizagem:

[...] de "escrever" a sua vida, o de "ler" a sua realidade, o que não será possível se não tornam a história nas mãos para, fazendo-a, por ela serem feitos e refeitos.

Daí que, nesta perspectiva crítica, se faça tão importante desenvolver, nos educandos como no educador, um pensar certo sobre a realidade. $E$ isto não se faz através de blá-blá-blá mas do respeito à unidade entre prática e teoria (FREIRE, 1981, p. 13).

A educação humanista e problematizadora, segundo Freire (1997), não admite a manipulação dos educandos e permite constantemente a reflexibilidade, assim como desperta a consciência crítica, ao contrário da educação bancária, que possibilita somente o depósito de informações, aliena e oprime.

Freire (1981, p. 40-41) ressalta que a opressão de alguns sujeitos ocorre por meio de uma "cultura do silêncio":

Como tal, não é o privilégio de uns poucos com que silenciam as maiorias. É exatamente por isto que, numa sociedade de classes, seja fundamental à cesse dominante estimular o que vimos chamando de cultura do silêncio, em que as classes dominadas se acham semimudas ou mudas, proibidas de expressar-se autenticamente, proibidas de ser.

Essa "cultura do silêncio" condiciona o "estar sendo" dos sujeitos e, nesse sentido, cabe uma reflexão a respeito dos processos de humanização e desumanização que, segundo o autor, caminham juntos, na busca do "ser para si" e do "ser mais".

A desumanização, conforme Freire (1981, p. 79), é revelada e entendida como alienadora e dominante e a humanização é compreendida como um sonho das classes dominadas que sofrem opressões. Tanto a desumanização quanto a humanização interferem "[...] na ação dos homens sobre a realidade social - a primeira, no sentido da preservação do 'status quo'; a segunda, no da radical transformação do mundo opressor".

A desumanização, que não se verifica, apenas, nos que têm sua humanidade roubada, mas também, ainda que de forma diferente, nos que a roubam, é distorção da vocação do ser mais. É distorção possível na história, mas não vocação histórica. $\mathrm{Na}$ verdade, se admitíssemos que é vocação histórica dos 
homens, nada mais teríamos que fazer, a não ser adotar uma atitude cínica ou de total desespero. A desumanização, que não se verifica, apenas, nos que têm sua humanidade roubada. A luta pela humanização, pelo trabalho livre, pela desalienação, pela afirmação dos homens como pessoas, como "seres para si", não teria significação. Esta somente é possível porque a desumanização, mesmo que um fato concreto na história, não é, porém, destino dado, mas resultado de uma "ordem" injusta que gera a violência dos opressores e esta, o ser menos (FREIRE, 1987, p. 16).

É necessária, portanto, uma "pedagogia utópica" que seja "concebida na prática realizada numa área significativa":

[...] Utópica e esperançosa porque, pretendendo estar a serviço da libertação das classes oprimidas, se faz e se refaz na prática social, no concreto, e implica na dialetização da denúncia e do anúncio, que tem na práxis revolucionária permanente, o seu momento máximo (FREIRE, 1981, p. 47-48).

A “ação cultural” proposta por Freire (1981, p. 30) não pode justapor-se à visão de mundo dos educandos, sendo invasiva culturalmente, porém precisa adaptar-se e partir dessa visão, pois o educador tem a tarefa de exercer com os educandos essa realidade posta como um problema, "[...] uma volta crítica sobre ela, de que resulte sua inserção, cada vez mais lúcida, na realidade em transformação".

Os professores, por sua vez, são cada vez mais desafiados no desenvolvimento de suas práticas educativas, em virtude de questões das mais diversas naturezas: ética, afetiva, política, social, ideológica e cultural, entre outras (FELDMANN, 2009).

$O$ interculturalismo elucida a diversidade cultural no espaço educativo e, consequentemente, é preciso que as diferentes culturas sejam compreendidas e contempladas nos currículos e práticas educativas, em conformidade com o que García (1990 apud GARCÍA, 1999) propõe em uma perspectiva de educação intercultural, a qual envolva o reconhecimento, a valorização dos diferentes grupos, no campo de conteúdos nos cursos formação inicial de professores, classifica-os em: Teoria, Sociedade e Classe, representados e sintetizados no Quadro 2:

Quadro 2: Conteúdos de formação inicial - propostos por García (1990 apud GARCÍA, 1999)

TEORIA - CONCEITOS/ TEORIZAÇÕES

Definições de cultura

Visões de diversidade cultual

Estudos de abordagens da cultura

\section{SOCIEDADE - CONTEXTUALIZAÇÃO}

Desenvolvimento histórico e os grupos na sociedade

Efeitos positivos e negativos da diversidade cultural no desenvolvimento da sociedade

Distinções entre características de classe social e atributos dos grupos culturais minorizados e dominantes

\section{CLASSE - ESTRATÉGIAS, RECURSOS DIDÁTICOS E MATERIAIS}

Efeito potencial das variáveis culturais e socioeconômicas
Potenciais de conflito e interação positiva


DOI: $10.12957 /$ teias.2021.62074

\begin{tabular}{|c|c|c|}
\hline $\begin{array}{l}\text { Métodos de estudo da cultura (escola e } \\
\text { comunidade) }\end{array}$ & $\begin{array}{c}\text { Semelhanças e diferenças entre } \\
\text { culturas }\end{array}$ & $\begin{array}{c}\text { Materiais e outros elementos do } \\
\text { ambiente }\end{array}$ \\
\hline $\begin{array}{l}\text { Conceitos de relativismo e } \\
\text { etnocentrismo }\end{array}$ & Diferentes estilos de vida & $\begin{array}{l}\text { Uso de métodos e técnicas } \\
\text { apropriados }\end{array}$ \\
\hline Conceitos de enculturação e aculturação & Tradições culturais & Diferentes estilos de comunicação \\
\hline Entre outros & Entre outros & Entre outros \\
\hline
\end{tabular}

Fonte: As pesquisadoras,2021 - Adaptado de (GARCÍA, 1990, p. 726 apud GARCÍA, 1999, p. 93).

Pérez Tapias (2013, p. 127) afirma que, em uma sociedade cada vez mais plural, "[...] a verdadeira educação democrática deve ser por força intercultural”. O autor destaca que, para haver o verdadeiro diálogo intercultural, é preciso reconhecer e até mesmo superar as desigualdades existentes na sociedade.

Ressalta-se o conhecimento acerca dos contextos e das culturas nos currículos e práticas educativas. É necessário que se compreenda, conforme destacam Feldmann e Masetto (2017, p. 566), a formação de educadores como uma "tríade: currículo, contexto e culturas". Os autores destacam a concepção de currículo como "[...] construção social e epistemológica do conhecimento [...]" que se materializa nas práticas, no âmbito escolar:

[...] e vivenciada em movimentos de tensões e lutas pela ocupação territorial dos saberes. A construção do currículo é delimitada por várias forças em conflito, e por processos de significações em diferentes contextos, que se realizam pela negociação de sentidos entre os sujeitos curriculares ao envolverem conhecimentos, valores, saberes e atitudes produzidos no intercruzamento de diversas culturas presentes. Assim, por se apresentar multirreferenciado epistemologicamente, carrega consigo a dimensão da incompletude, não entendida como superficialidade, mas como inacabamento que compõe a condição humana em seu projeto de vir a ser (FELDMANN; MASETTO, 2017, p. 567).

Outrossim, a interculturalidade crítica precisa ser concebida como um projeto político e social, segundo salientam Santiago, Akkari, Marques (2013). Nessa acepção exige-se:

Uma pedagogia que afirme as diferenças em seus aspectos histórico-políticosociais e de poder. No que se refere à construção de práticas educativas orientadas por uma perspectiva intercultural, o trabalho requer que seja oferecido aos estudantes múltiplas situações que permitam compreender o mundo a partir de diferentes formas sócio-históricas que possibilitem a reflexão sobre o seu próprio contexto e sobre outras realidades (MARTÍNEZ et al., 2009 apud SANTIAGO; AKKARI; MARQUES, 2013, p. 27).

Possibilita-se, desse modo, segundo os autores, o rompimento de concepções no que tange a saberes reproduzidos tradicionalmente, considerados como "dados" e "universais", com a possibilidade de criação e recriação a partir das experiências históricas e de forma contextualizada, integrado aos diferentes conhecimentos e saberes produzidos pelos grupos humanos. 
Na educação ou "ação cultural" libertadora, para Freire (1981, p. 80-81), tanto os educadores quanto os educandos ensinam e aprendem:

[...] em lugar de ser aquela alienante transferência de conhecimento, é o autêntico ato de conhecer, em que os educandos - também educadores - como consciências "intencionadas" ao mundo ou como corpos conscientes, se inserem com os educadores - educandos também - na busca de novos conhecimentos, como consequência do ato de reconhecer o conhecimento existente. Mas - não será demasiado reenfatizar - para que a educação, como prática da libertação, possa tentar a realização de um tal reconhecimento do conhecimento existente, de que decorre a procura de novos conhecimentos, jamais pode fazer coincidir sua forma de "tratar" a consciência do homem com o modo pelo qual a "trata" a educação dominadora. Daí a necessidade a que fizemos referência anteriormente de o educador, que fez a opção humanista, perceber corretamente as relações consciência-mundo ou homem-mundo.

Destarte, revela-se a necessidade de reinvenção dos currículos, sobretudo o de formação inicial de professores, de modo que se reconheçam e se acolham adequadamente as diversidades culturais e se possibilitem as vozes dos diferentes sujeitos. Entendemos esperançosamente que a "ação cultural", conforme concebida por Freire (1981), com o interculturalismo, pode ser uma possibilidade para esse caminho de busca por uma humanização e sociedade mais justa.

Quilombos ainda existem? Valorização e visibilidade dos/aos povos excluídos que construíram a sociedade brasileira

São poucas ou inexistentes nossas memórias acerca da história e/ou sobre os quilombos, que sofreram um apagamento na sociedade e nas discussões educacionais e curriculares, as referências que comumente nos são reportadas, apresentam resquícios do período colonial imperial. Todavia, as comunidades quilombolas vivem, resistem e reexistem desde o século XVI em que se constituíram diversos quilombos no Brasil, como uma forma de resistência ao escravismo e de organização da sociedade. Como "[...] uma pátria africana no Brasil e um núcleo de liberdade para os nascidos aqui" (CHIAVENATO, 2012, p. 138).

Conforme reafirma o documento Brasil (2013, p. 59 - grifo nosso):

Nas comunidades remanescentes de quilombos, o acesso à escola para as crianças é difícil, os meios de transporte são insuficientes e inadequados, e o currículo escolar está longe da realidade desses meninos e meninas. Raramente os alunos quilombolas veem sua história, sua cultura e as particularidades de sua vida nos programas de aula e nos materiais pedagógicos.

Nessa acepção, realça-se que há um total desconhecimento a respeito da existência das comunidades quilombolas na contemporaneidade, porque elas são invisibilizadas e a história não é contada em sua totalidade, congelando os quilombos no período escravocrata, ou ainda é permeada por estereótipos e preconceitos, em que se justificam suas constituições por meio do binômio fuga e isolamento, em conformidade com Santos (2011, p. 5 - grifo nosso), ao citar o documento Regulamento da Câmara de São Paulo 1740 , o qual denomina quilombo como: “[...] ajuntamento de mais de quatro escravos [...]" que fugiam para os matos para ali cometerem homicídios, roubos e atrocidades. Entretanto, segundo a autora: 
[...] novos estudos a respeito desse período da nossa história demonstram que os quilombos se constituíram a partir de uma grande diversidade de processos, sendo que as fugas com ocupação de terras livres eram apenas uma dentre outras estratégias de luta pela liberdade. Assim temos ocupação de terras recebidas por heranças, doações, recebimento de terras como pagamento de serviços prestados ao Estado, permanência nas terras que ocupavam e cultivavam no interior das grandes propriedades e a compra de terras durante a vigência do sistema escravocrata. Portanto, com atitudes originais essa população construiu um espaço autônomo dentro do regime escravista que possibilitou a sua sobrevivência física e cultural. Eles também não viviam isolados, pois mantinham um sistema de aliança com seus vizinhos e comercializavam seus produtos agrícolas nas cidades (SANTOS, 2011, p. 6).

A resposta para a questão inicial não parece óbvia, mas, $\operatorname{sim}(!)$, há diversas comunidades quilombolas na contemporaneidade, tanto urbanas quanto rurais. Estima-se que no Brasil existem mais de 3.500 comunidades, nas variadas regiões, conforme dados da Fundação Cultural Palmares (FCP). As comunidades quilombolas nunca deixaram de existir.

De acordo com o documento do Instituto Nacional de Colonização e Reforma Agrária (INCRA, 2017, p. 10), "Regularização de território quilombola perguntas \& respostas":

Constata-se, por meio dos estudos realizados pelo INCRA e outros órgãos oficiais, que a grande maioria das com unidades quilombolas são rurais, dedicadas à agricultura, ou seja, nos quilombos é praticado o plantio de alimentos, a pecuária de grandes e pequenos animais, a pesca, o extrativismo, e várias outras atividades que são consideradas agrícolas. Em sua maioria, estas atividades são realizadas não só para o sustento da comunidade, mas também para o fornecimento ao mercado local, contribuindo para o desenvolvimento tanto das comunidades como da região em que estão inseridas.

O Quadro 3 apresenta o quantitativo das comunidades quilombolas já reconhecidas pela FCP até o ano de 2020, sem contar aquelas que se encontram em fase de reconhecimento; totalizam cerca de 5.000 mil.

\begin{tabular}{|l|c|}
\hline \multicolumn{2}{|c|}{ Quadro 3: Comunidades quilombolas reconhecidas pela FCP por região } \\
\hline \multicolumn{1}{|c|}{ REGIÃO } & CQ RECONHECIDAS \\
\hline$\bullet$ Nordeste & $\bullet 2.184$ \\
\hline$\bullet$ Sudeste & $\bullet 541$ \\
\hline$\bullet$ Sorte & $\bullet 369$ \\
\hline$\bullet$ Centro-Oeste & $\bullet 192$ \\
\hline
\end{tabular}

Fonte: As pesquisadoras, 2021 - Adaptado de: http://www.palmares.gov.br/wpcontent/uploads/2015/07/TABELA-DE-CRQ-COMPLETA-QUADRO-GERAL-29-10-2020-1.pdf . Acesso em 3 mai. 2021.

O referido quadro demonstra que a maior concentração das comunidades quilombolas encontra-se na região Nordeste, seguida da região Sudeste. Na região Sudeste, 402 estão localizadas 
no estado de Minas Gerais, seguido de 56 em São Paulo, 42 situadas no Espírito Santo e 41 no Rio de Janeiro.

Até a promulgação da Constituição Federal de 1988, há uma lacuna na história a respeito dos quilombos. A referida lei trouxe uma ressignificação ao termo em seu artigo 68, ao denominálas de "comunidades remanescentes de quilombo" (CRQ): "[...] Aos remanescentes das comunidades dos quilombos que estejam ocupando suas terras é reconhecida a propriedade definitiva, devendo o Estado emitir-lhes os titulos respectivos" (BRASIL, 1988, p. 138 - grifo nosso).

Embora se reconheça o avanço com a promulgação da lei, esta não trouxe um melhor detalhamento do processo de reconhecimento dessas comunidades e somente em 2003 houve a publicação do Decreto n. ${ }^{\circ} 4.887$, de 20 de novembro de 2003, que em seu artigo 2. ${ }^{\circ}$ estabelece mais explicitamente esses procedimentos e considera as CRQ:

[...] os grupos étnico-raciais, segundo critérios de autoatribuição, com trajetória histórica própria, dotados de relações territoriais específicas, com presunção de ancestralidade negra relacionada com a resistência à opressão histórica sofrida (BRASIL, 2003, p. 1).

Um dos aspectos centrais de símbolo da herança cultural, material e de resistência dos povos quilombolas é a luta pelo território, porque muitas delas não possuem o título de propriedade definitiva, conforme preconizam as leis, embora haja um avanço em matéria de legislação e garantias de direitos, fazem-se necessários infindáveis lutas contra a exclusão e a relegação desses direitos, uma marca do período colonial que prevalece até os dias atuais.

Segundo informações extraídas do portal da Fundação Instituto de Terras do Estado de São Paulo "José Gomes da Silva" (ITESP, 2007, s.p.):

Essas comunidades têm uma história de luta pela liberdade, desde que seus antepassados foram trazidos da África como escravos, e hoje lutam por um pedaço de terra onde possam viver de acordo com suas tradições. Outra característica marcante é a ocupação do território de acordo com ligações de parentesco.

Além da resistência à escravidão por meio de formas de organização próprias, as comunidades quilombolas sempre foram ricas em sua diversidade (LOBÃO, 2014) e reexistem na contemporaneidade manifestadas nas mais diversas formas de herança cultural e imaterial, por meio das linguagens, religiões, músicas, danças, artes, culinária, agricultura tradicional incluindo as formas de produção sustentáveis e de proteção ao meio ambiente, entre outras.

No que tange à educação dos povos quilombolas, apesar de em 2010 a Educação Escolar Quilombola (EEQ) ser reconhecida como uma modalidade da Educação Básica por meio do Parecer CNE/CEB n. ${ }^{\circ} 7 / 2010$ e Resolução CNE/CEB n. ${ }^{\circ} 4$, de 13 de julho de 2010, e reafirmada em 2012 com a publicação do Parecer CNE/CEB n. ${ }^{\circ}$ 16/2012 e Resolução CNE/CEB n. ${ }^{\circ}$ 8, de 20 de novembro de 2012, ainda há muitos desafios para sua implementação nas mais diversas regiões do Estado, que em sua grande maioria não adotaram legislações específicas para o atendimento à referida lei.

Segundo a Resolução CNE/CEB n. ${ }^{\circ}$ /2012, a EEQ organiza o ensino nas instituições educacionais que precisam evidenciar, entre outros elementos, além de necessitarem ser abertos e flexíveis, devem fundamentar-se, informar-se a alimentar-se de alguns referenciais conforme apresentado na figura 1. 
Figura 1: Eixos centrais da EEQ

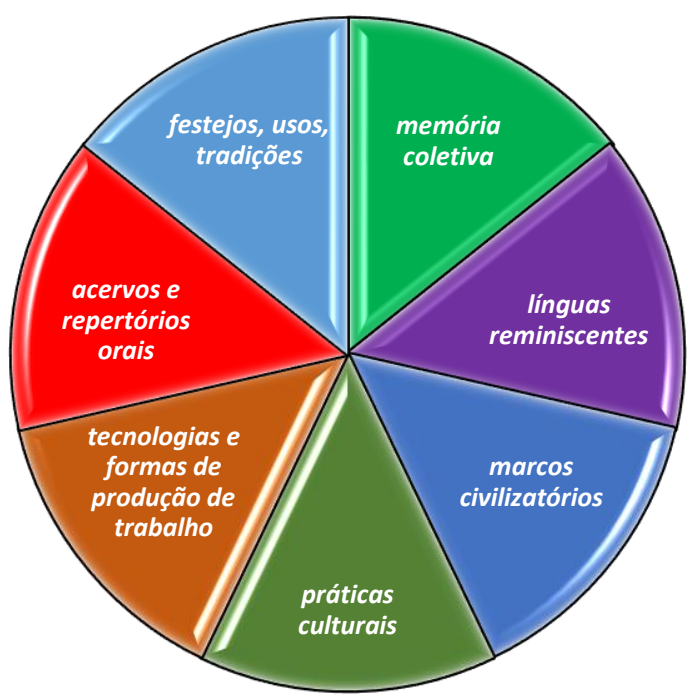

Fonte: Adaptado de (BRASIL, 2012, p. 3).

Apesar de ser notória a contribuição dos povos quilombolas na constituição da sociedade brasileira, eles ainda não são relembrados ou reconhecidos no âmbito das instituições de ensino, fruto da segregação e racismo herdados do projeto colonial. Assinala-se, assim, a necessidade de avivamento desses povos nos currículos e práticas educativas:

De acordo com a Organização das Nações Unidas para a Educação, a Ciência e a Cultura (UNESCO), o que caracteriza o Brasil como um dos países mais ricos, em termos culturais, é sua diversidade étnico-racial. No entanto, nossa história é marcada por desigualdades e discriminações, particularmente contra negros e indígenas, como sabemos, e diversos estudos comprovam. Porém, a única forma de superação dos conflitos, do preconceito, da discriminação e da segregação racial, com vista à promoção da igualdade de direitos e justiça social, está na elucidação das contribuições dos distintos povos na construção da sociedade brasileira (MÜLLER; COELHO, 2013, p. 15 - grifo nosso).

Tal aspecto de apagamento e invisibilidade também pode ser evidenciado nos estudos que temos realizado, em que é notória a ausência dos povos e/ou comunidades quilombolas nos currículos de formação inicial de professores de uma Instituição de Ensino (IE), ou a insuficiência dela, com concepções e enfoques genéricos, superficiais e até mesmo carregados de estereótipos, conforme atitudes de um "currículo turístico", abordando pouco a diversidade cultural de modo distanciado, não refletindo os tipos de dominação e opressão, conforme apresentado por Santomé (2013). Entretanto, faz-se necessária, segundo o autor, uma pedagogia crítica e emancipadora "antimarginalização" na construção de um projeto e intervenção curricular em que educadores e educandos estejam comprometidos com a luta político-cultural.

Uma "pedagogia utópica" que, segundo Freire (1981, p. 48-49), seja:

[...] da denúncia e do anúncio tem de ser um ato de conhecimento da realidade denunciada, [...] enquanto ação cultural para a libertação. Daí a ênfase que damos 
à constante problematização da realidade concreta [...], representada em situações codificadas.

Quanto mais a problematização avança e os sujeitos descodificadores se adentram na "intimidade" do objeto problematizado, tanto mais se vão tornando capazes de desvelá-lo.

À vista disso, considera-se de suma importância um olhar atento e sensível para os currículos, bem como para as práticas escolares, de modo que se reconheçam as especificidades das comunidades quilombolas e valorizem-se esses povos, desde a formação inicial dos professores, uma vez que a EEQ constitui-se como uma Modalidade da Educação Básica que perpassa todas as etapas e modalidades: “[...] Educação Infantil, Ensino Fundamental, Ensino Médio, Educação do Campo, Educação Especial, Educação Profissional Técnica de Nível Médio, Educação de Jovens e Adultos, inclusive na Educação a Distância [...]” (BRASIL, 2012, p. 3).

Portanto, Arroyo (2013) elucida acerca da importância de se repolitizar o currículo no âmbito escolar, por meio desses "coletivos" considerados "empobrecidos" como os sujeitos quilombolas, a partir de suas próprias histórias, vozes, contestando o que é colocado como natural e problematizando a realidade e as desigualdades, assim como nos ensina Freire.

\section{CONSIDERAÇÕES FINAIS}

Evidenciamos, por meio deste estudo, que, embora pareça uma resposta óbvia à pergunta "Culturas são invisibilizadas nos currículos?” (sim, culturas são silenciadas nos currículos, seja no âmbito escolar ou no de formação de professores), é necessária uma reflexão a respeito dessa concepção de invisibilidade a fim de compreender sua complexidade diante das diversidades e desigualdades existentes, de modo a buscar caminhos mais humanizadores que visem à libertação dos sujeitos e à transformação da realidade excludente.

Para tanto, faz-se necessário também o entendimento dos currículos como territórios contestados e permeados por relações de poder, porque é preciso contrapor para quiçá reinventar essas estruturas hegemônicas que se constituem no cerne das instituições escolares e refletem na reprodução de determinada cultura homogeneizadora da sociedade, a classe dominante, tanto nas políticas públicas como nos currículos e nas práticas educativas, os quais comumente relegam determinadas culturas e povos, como é o caso dos sujeitos quilombolas que sofreram um apagamento histórico e evidentemente ainda são invisíveis na contemporaneidade.

As contribuições freireanas para uma educação humanizadora propõem uma educação crítica, transformadora, pautada pela construção e reconstrução do conhecimento a partir da realidade dos educandos, bem como por meio da problematização para nela intervir. A educação ou "ação cultural" não pode ser invasiva à cultura dos sujeitos, pelo contrário, deve partir dela. A concepção humanista não admite a prática de uma educação bancária em que se deposita "conhecimento" de forma isolada da realidade dos homens, porém requer uma educação amorosa, utópica, esperançosa, dialógica, participativa e emancipadora que possibilite a problematização constante com o "quefazer" problematizador dos educandos por meio do diálogo e das relações com o mundo.

Os currículos que cunham a EEQ precisam refletir e contemplar as especificidades e as diferentes contribuições dos povos e sujeitos quilombolas, assim como suas vozes precisam estar presentes. Destaca-se, assim, a importância do conhecimento dessa modalidade de educação na Educação Básica desde a formação inicial de professores, considerando as mais diversas comunidades quilombolas existentes, que resistem à opressão histórica sofrida, nas mais variadas 
regiões dos estados brasileiros, mantendo e preservando suas riquezas e diversidades culturais, portanto fazem-se necessários tanto o conhecimento por parte dos professores formadores quanto dos futuros professores acerca dessa modalidade de ensino.

Logo, compreendemos a relevância do reconhecimento e da valorização da dimensão cultural nos cursos de formação de professores, sob uma perspectiva intercultural em que, além de reconhecer e valorizar as diferentes culturas, é necessário preciso acolhê-las, respeitá-las e também admitir a existência das desigualdades. Por conseguinte, um "currículo turístico" não dá conta e não abarca em sua essência essas questões, que não podem mais ficar à margem das discussões e das políticas educacionais.

Revela-se, ainda, a necessidade da compreensão e de um olhar mais sensível a respeito do apagamento, ausência ou silenciamento de determinadas culturas nos currículos escolares e de formação de professores em detrimento de uma cultura dominante e hegemônica e, a partir das contribuições freireanas, evidencia-se que o caminho para a humanização dessas culturas, intermediada por uma pedagogia crítica e emancipadora para libertação e "antimarginalização", precisa partir do "ser para si" no que concerne a suas próprias histórias e de suas realidades concretas, de modo a reconhecer-se e acolher suas especificidades e diversidade cultural, bem como a busca do "ser mais" por meio de suas vozes e relações com o mundo. Ademais, fazemse necessários a visibilidade e o conhecimento sobre os povos/comunidades quilombolas que contribuíram e contribuem com a constituição da sociedade brasileira

\section{REFERÊNCIAS}

ARROYO, Miguel González. Os coletivos empobrecidos repolitizam os currículos. In: SACRISTÁN, José Gimeno (org.). Saberes e incertezas sobre o currículo [recurso eletrônico]. Tradução Alexandre Salvaterra. Revisão técnica Miguel González Arroyo. Porto Alegre: Penso, 2013. p.108125.

BRASIL. Constituição (1988). Constituição da República Federativa do Brasil de 1988. Disponível em http://www.planalto.gov.br/ccivil_03/constituicao/constituicao.htm. Acesso em 1. ${ }^{\circ}$ abr. 2021.

BRASIL. Decreto n. ${ }^{\circ}$ 4.887, de 20 de novembro de 2003. Regulamenta o procedimento para identificação, reconhecimento, delimitação, demarcação e titulação das terras ocupadas por remanescentes das comunidades dos quilombos de que trata o art. 68 do Ato das Disposições Constitucionais Transitórias. 2003.2 Disponível em http://www.planalto.gov.br/ccivil_03/decreto/2003/D4887.htm. Acesso em 27 abr. 2021.

BRASIL. Plano Nacional de Implementação das Diretrizes Curriculares Nacionais para a Educação das Relações Étnico-Raciais e para o Ensino de História e Cultura Afro-Brasileira e Africana. Secretaria de Políticas de Promoção de Igualdade Racial (SECADI). Brasília. 2013.

BRASIL. Ministério da Educação. Resolução CNE/CEB n. ${ }^{\circ}$, de 20 de novembro de 2012. Define Diretrizes Curriculares Nacionais para a Educação Escolar Quilombola na Educação Básica. Disponível http:/ / portal.mec.gov.br/index.php?option $=$ com_docman\&view $=$ download\&alias $=11963$ rceb008-12-pdf\&category_slug=novembro-2012-pdf\&Itemid=30192 Acesso em 27 abr. 2021. CHIAVENATO, Júlio José. O negro no Brasil. São Paulo: Cortez, 2012.

CHIZZOTTI, Antônio. Pesquisa qualitativa em ciências humanas e sociais. 6. ed. Petrópolis: Vozes, 2014. 
FELDMANN, Marina Graziela. (Org.). Formação de professores e cotidiano escolar. In. FELDMANN, Maria Graziela. Formação de professores e a escola na contemporaneidade. São Paulo. Editora Senac, 2009. p. 71-81.

FELDMANN, Marina Graziela; MASETTO, Marcos Tarciso. Formação de educadores: currículo, culturas e contextos. Revista e-Curriculum, Programa de Pós-Graduação em Educação: Currículo, São Paulo, 2017. Disponível em https:/ / revistas.pucsp.br. Acesso em 3 maio 2021.

FREIRE, Paulo. Ação cultural para a liberdade e outros escritos. 5. ed. Rio de Janeiro: Paz e Terra, 1981. FREIRE, Paulo. Pedagogia do oprimido. 17. ed. Rio de Janeiro: Paz e Terra, 1987.

FREIRE, Paulo. Papel da educação na humanização. Revista da FAEEBA, Salvador, n. 7, jan./jun. 1997.

GARCÍA, Carlos Marcelo. Formação de professores para uma mudança educativa. Portugal: Porto Editora,1999. Cap. 2.

INCRA - Instituto Nacional de Colonização e Reforma Agrária. Regularização de território quilombola perguntas \& respostas. Diretoria de Ordenamento da Estrutura Fundiária. Coordenação Geral de Regularização de Territórios Quilombolas - DFQ. Atualizado em 13/04/2017. Disponível em https://www.gov.br/incra/pt-br/assuntos/governanca-fundiaria/perguntas_respostas.pdf.

Acesso em 4 maio 2020.

ITESP - FUNDAÇÃO INSTITUTO DE TERRAS DO ESTADO DE SÃO PAULO "JOSÉ GOMES DA SILVA". Perguntas Frequentes. 2007. Disponível em http://www.itesp.sp.gov.br/br/info/instituicao/faq.aspx . Acesso em 5 mai. 2021.

LOBÃO, Alexandre. Quilombos e quilombolas: passado e presente de lutas. Belo Horizonte: Mazza Edições, 2014.

MÜLLER, Tânia Mara Pedroso; COELHO, Wilma de Nazaré Baía (org.). Relações étnico-raciais e diversidade. Niterói: Editora da UFF, Alternativa, 2013.

PÉREZ TAPIAS, José Antonio. Educar a partir da interculturalidade: exigências curriculares para o diálogo entre culturas. In: SACRISTÁN, José Gimeno (org.). Saberes e incertez̧as sobre o currículo [recurso eletrônico]. Tradução Alexandre Salvaterra. Revisão técnica Miguel González Arroyo. Porto Alegre: Penso, 2013. p. 126-136.

SILVA, Tomaz Tadeu da. Documentos de identidade: uma introdução às teorias do currículo. Belo Horizonte: Autêntica, 2016.

SANTIAGO, Mylene Cristina; AKKARI, Abdeljalil; MARQUES, Luciana Pacheco. Educaşão intercultural: desafios e possibilidades. Petrópolis: Vozes, 2013.

SANTOMÉ, Jurjo Torres. As culturas negadas e silenciadas no currículo. In: SILVA, Tomaz Tadeu da (org.). Alienigenas na sala de aula. 11. ed. Petrópolis: Vozes 2013. p. 155-172.

SANTOS, Patrícia Scalli dos. Relatório Técnico Científico - RTC - Quilombo de Peropava. Instituto de Terras do Estado de São Paulo - ITESP. 2011. 


\section{Informações do(a)(s) autor(a)(es)}

Marina Graziela Feldmann

Pontifícia Universidade Católica de São Paulo - PUC-SP

E-mail: feldmann@uol.com.br

ORCID: http://orcid.org/0000-0003-3008-2636

Link Lattes: http://lattes.cnpq.br/5107177703842569

Andréia Regina Silva Cabral Libório

Instituto Federal de Educação, Ciência e Tecnologia de São Paulo - IFSP/ Pontifícia Universidade Católica de São Paulo (PUC-SP)

E-mail: andreia.rsc20@gmail.com

ORCID: https://orcid.org/0000-0002-7457-220X

Link Lattes: http://lattes.cnpq.br/9955006282999951 